\title{
Recent Insights on Lithium-Ion Batteries Recycling
}

ISSN: 2578-0255

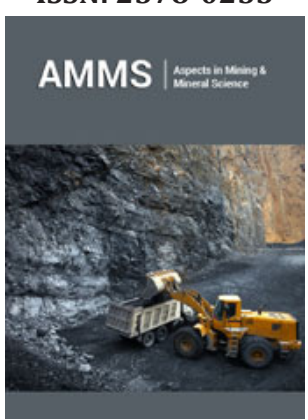

*Corresponding author: Alexandre Chagnes, Université de Lorraine, Labex Ressources 21, CNRS, GeoRessources, 54000 Nancy, France

Submission: March 10, 2020

Published: 海 May 13, 2020

Volume 4 - Issue 5

How to cite this article: Alexandre Chagnes. Recent Insights on Lithium-Ion Batteries Recycling. Aspects Min Miner Sci. 4(5). AMMS.000598. 2020.

DOI: 10.31031/AMMS.2020.04.000598

Copyright@ Alexandre Chagnes, This article is distributed under the terms of the Creative Commons Attribution 4.0 International License, which permits unrestricted use and redistribution provided that the original author and source are credited.

\author{
Alexandire Chagnes* \\ Université de Lorraine, France
}

\begin{abstract}
Lithium-ion battery is the technology of choice in the development of electric vehicles. This technology is now mature although there are still many challenges such as increase of energy density, safety as well as development of lithium-ion batteries recycling processes. This article aims at introducing recent development in hydrometallurgy in order to produce sustainable lithium-ion batteries within the framework of energy transition and electric mobility. The development of recycling processes, including solvent extraction to recover value metals from spent lithium-ion batteries such as nickel, cobalt, manganese and lithium relies both the design of new extracting agents and the optimization of flowsheet operating conditions. For this goal, new modelling tools have to be developed. This paper gives a minireview on recycling of lithium-ion batteries including recent insights.
\end{abstract}

Keywords: Lithium-ion battery, Recycling, Resources, Electric vehicles

\section{Introduction}

Our society is undergoing a profound transformation with the realization that we must manage our resources sustainably. The energy transition is at the heart of our concerns. We must be able to produce and store energy while being respectful of our environment. We also need to drastically cut our carbon dioxide emissions to reduce the impact of human activities on climate change. The energy transition is based on suitable electricity production and storage technologies such as solar panels, wind turbines, nuclear reactors, lithium-ion batteries, fuel cells, but also on the sustainable extraction of metals contained in minerals that are needed to make these technologies. Most countries are aware of the issues surrounding these mineral resources, particularly with regard to self-sufficiency in supply. Even if secondary resources from recycling or residues from industrial and mining activities can never meet all the needs of a country in full economic growth, it is clear that secondary resources remain an opportunity for diversification not to be neglect. Among the storage technologies mentioned above, lithium-ion batteries are the subject of particular attention because they are currently considered as the best solution for the development of electric vehicles. This technology is now mature, although there are still many challenges to meet new applications that are increasingly energy intensive. For example, the development of electric vehicles in the short term requires increasing the energy density of batteries while ensuring impeccable safety of use. For this, it is necessary to develop new positive electrode materials which can cycle at higher voltages and electrolytes compatible with these materials [1]. But the challenge is not only about the production of high-performance objects to store energy electrochemically. Indeed, the components of lithium-ion batteries are made from natural resources, some of which are critical and lead, at the end of their life, to a polluting product. From the design of the batteries, it is therefore necessary to think about the supply of resources to design them but also about the means of recycling them.

The lithium-ion battery operates on the reversible exchange of lithium ion between a positive electrode, most often a lithium transition metal oxide denoted $\mathrm{LiMeO}$ and a negative graphite electrode (Figure 1). Lithium-ion batteries are made up of an electrolyte soaked in a polypropylene-polyethylene separator. This electrolyte is composed of a mixture of organic dipolar aprotic solvents of the family of alkyl carbonates most often, in which is dissolved a lithium salt at $1 \mathrm{~mol} \mathrm{~L}^{-1}\left(\mathrm{LiPF}_{6}, \mathrm{LiBF}_{4}\right.$ or LiTFSI currently). The negative electrode, made 
of graphite, has hardly changed since the first lithium-ion battery put on the market. Indeed, graphite is used in most lithium-ion technologies even if other materials such as silicon are starting to find interesting applications [2]. Much research has focused on the development of positive electrodes such as $\mathrm{LiCoO}_{2}, \mathrm{LiNiO}_{2}$,
$\mathrm{LiMn}_{2} \mathrm{O}_{4}$ to meet many applications that require energy storage. Today, polymetallic electrodes such as NMC electrodes which are lithiated oxides of nickel, manganese and cobalt exhibiting various stoichiometries are the most used, especially for laptops but also for the electric vehicle.

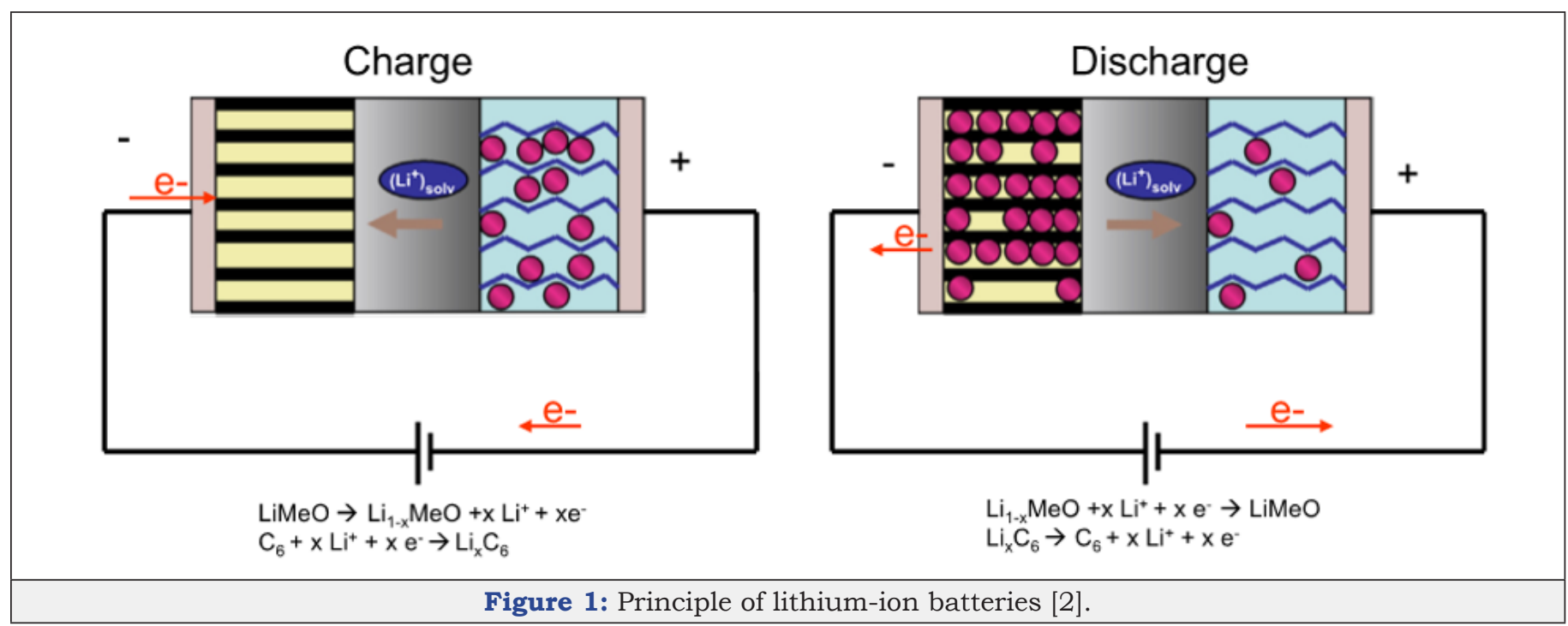

Cobalt, nickel, manganese and lithium are therefore today key elements for the production of lithium-ion batteries and the development of electric vehicles. Given the large electric vehicle market, we can therefore expect significant growth in demand for these metals, but also a spike in price and an increase in tensions. Demand is therefore expected to increase by thirty-one for cobalt, sixty-nine for nickel and forty-six for lithium by 2030 compared to 2017 according to Avicenne [3]. The supply of cobalt, nickel, manganese and lithium (but also graphite and fluorine which are the other key elements for the production of lithium-ion batteries) makes it necessary to develop efficient, economical, and sustainable processes capable to recover these metals from both primary resources and spent lithium-ion batteries. This article will limit itself to briefly presenting the challenges in the recycling of lithium-ion batteries.

\section{Recycling of Lithium-Ion Batteries}

Most of the current lithium-ion battery recycling processes use a pyrometallurgical route or the combination of pyrometallurgical and hydrometallurgical operations. For example, the Umicore process, initially developed for the recovery of spent lithiumion batteries contained in mobile phones, is based on the use of furnaces at $1400{ }^{\circ} \mathrm{C}$ after a deep discharge for safety reasons. It is then possible to recover, at the outlet of the furnace, a slag containing in particular non-recoverable aluminum and lithium, and a metal alloy treated by selective leaching in order to extract iron and copper separately. The graphite in the negative electrodes and the solvent in the electrolyte are burnt and generate carbon dioxide. The cobalt and the nickel are then separated by liquid-liquid extraction in chloride medium. More and more studies are turning to purely hydrometallurgical routes in order to be able to recover the maximum of metals contained in spent lithium-ion batteries.
The diagram in Figure 2 shows the main steps to be implemented in the hydrometallurgical recycling processes of lithium-ion batteries. The batteries must undergo a deep discharge for safety reasons in order to be dismantled so as to eliminate the electronics, plastics, and the carcass which could be reused. It is then conceivable to recover the solvent and salt by vacuum distillation, then to separate the copper and aluminum current collectors from the active material by dissolving the solvent [4]. The active material can optionally be ground before undergoing a leaching step aimed at dissolving the cobalt, nickel, manganese and lithium contained in the positive electrodes. These metallic species can then be extracted separately, with suitable technology (liquid-liquid extraction, extraction by ion-exchange resin, precipitation, etc.) before precipitating the metal salts to the desired purity. Dismantling is tedious because batteries are complex objects. The robotization of this step could reduce the costs of this operation. The solubilization of binders involves the use of toxic solvents. Another approach would be to grind the battery under inert flow or under water, to implement physical separation/concentration operations and then to treat the concentrate by hydrometallurgy by means of sulfuric acid leaching in the presence of hydrogen peroxide. Cobalt-nickel separation can be easily performed by liquid-liquid extraction while manganese(cobalt-nickel) separation is more complex to implement. For this, reducing precipitation can be considered. The hydrometallurgical route should also allow lithium to be recovered, for example by using suitable adsorbent materials. In all cases, the treatment of lithiumion batteries by grinding under water will generate significant quantities of effluents to be treated containing lithium salts and organic solvents. Cost-effective treatment technologies will have to be developed to treat these effluents without generating too much ultimate residue like electrodialysis [5]. 


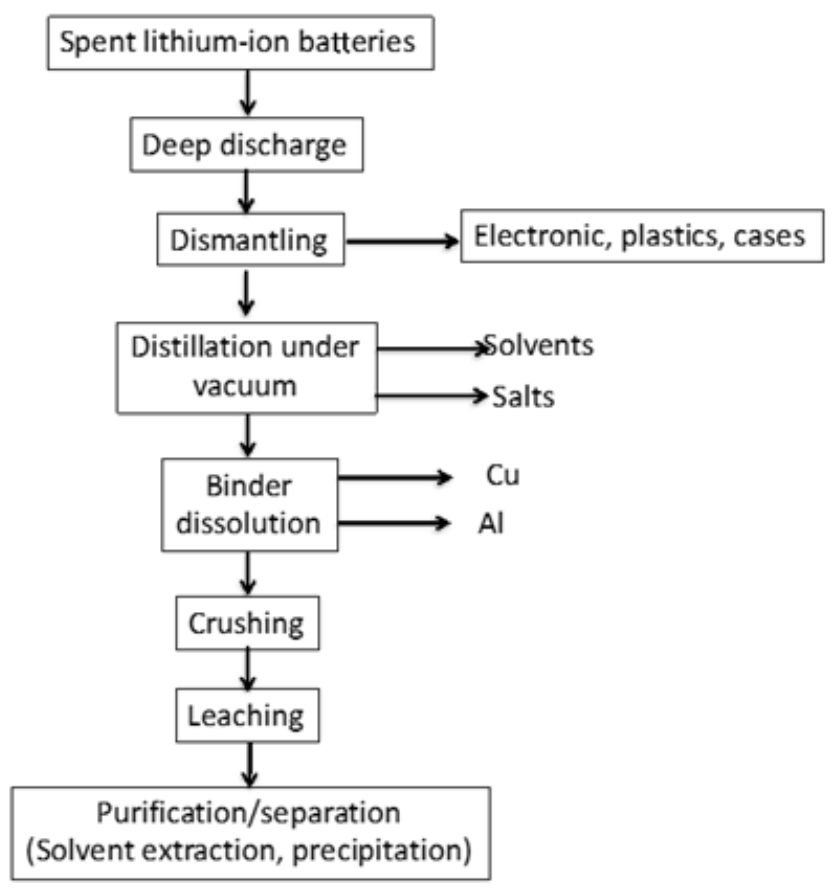

Figure 2: Illustration of a flowsheet for recycling spent lithium-ion batteries [4].

Recycling processes have to be very flexible because of the huge number of different lithium-ion batteries available on the market (NMC with different stoichiometries, $\mathrm{LiFePO}_{4}, \mathrm{LiMn}_{2} \mathrm{O}_{4}$ and high energy density cathodes in the next decade or the development of other technologies such as lithium-sulphur or lithium-air batteries around 2040). Furthermore, design of recycling plants will depend on the amount of lithium-ion batteries to recycle, which can change depending on the electrochemical storage devices available on the market for electric vehicle or stationary applications (redox flow battery, fuel cell, sodium-ion batteries, etc.). For all of these reasons, the development of recycling processes for lithium-ion batteries is particularly tricky. It means that it is mandatory to develop recycling processes that can adapt to changes in composition and volumes of the inlet streams. Such flexible processes must rely on artificial intelligence. However, artificial intelligence requires huge amount of data. In order to reduce the amount of data requested to operate efficiently a process, it seems of great interest to combine artificial intelligence with a physical models as illustrated in (Figure 3) for solvent extraction processes.

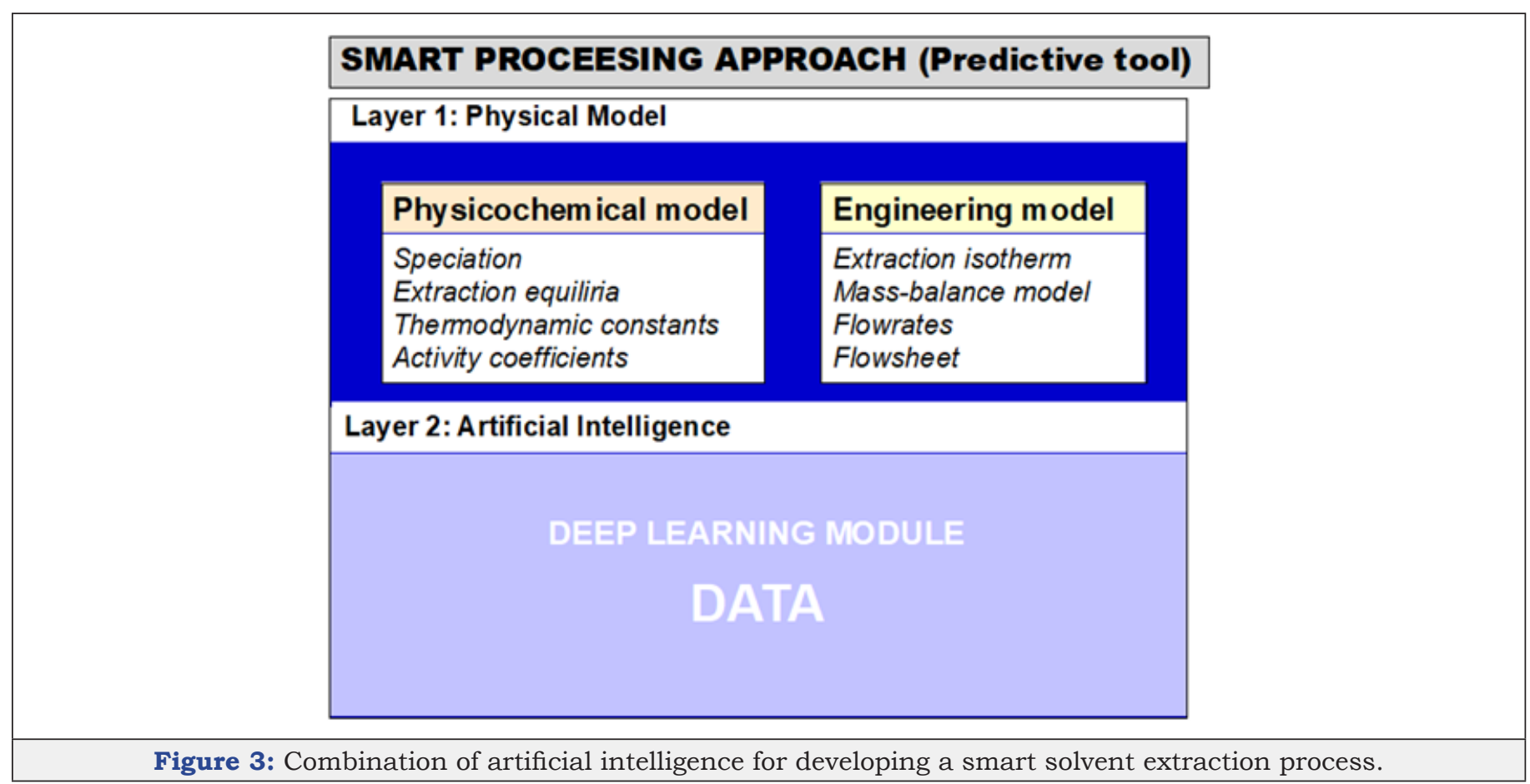


Recently, Chagnes et al. [6-9] developed the physical model to describe solvent extraction of cobalt, nickel, manganese from acidic media that could be produced by leaching positive electrode of spent lithium-ion batteries. This model is the first layer of a more tool involving Artificial Intelligence that could be used for optimizing recycling processes or for improving process efficiency.

\section{Conclusion}

There are still few players involved in the recycling of lithiumion batteries, but the expected emergence of electric vehicles will necessarily stimulate the development of a recycling chain for lithium-ion batteries. It is a complex sector to implement because lithium-ion batteries are complex objects and because there is not a single type of lithium-ion battery but almost as many batteries as there are applications. It is also a complex object because lithiumion technology is evolving rapidly. We must therefore imagine flexible recycling processes. In order to facilitate the work of recyclers, it seems important to quickly integrate the recycling issue into battery production by favoring an eco-design approach for the battery to facilitate its dismantling (using a robot for example), and eco-design of materials by finding the best compromise between performance and ease of implementation of recycling (substitution of materials).

\section{Acknowledgement}

This work was supported by the national program "Investissements d'avenir" with the reference ANR-10-LABX-21RESSOURCES21.

\section{References}

1. Flamme B, Garcia GR, Weil M, Haddad M, Phansavath $P$, et al. (2017) Guidelines to design electrolytes for lithium-ion batteries: environmental impact, physicochemical and electrochemical properties. Green Chemistry 19: 1828-1849.

2. Chagnes A (2015) Lithium battery technologies: electrolytes. In: Chagnes A, Swiatowska J (Eds.), Lithium process chemistry: resources, extractions, batteries and recycling. $1^{\text {st }}$ edn, Amsterdam: Elsevier, Netherlands, pp. 167-189.

3. Pillot C (2018) The rechargeable battery market and main trends 20172025. Avicenne Energy.

4. Chagnes A, Pospiech B (2013) A brief review on hydrometallurgical technologies for recycling spent lithium-ion batteries. Journal of Chemical Technology and Biotechnology 88(7): 1191-1199.

5. Gmar S, Chagnes A (2019) Recent advances on electrodialysis for the recovery of lithium from primary and secondary resources. Hydrometallurgy 189: 105124.

6. Omelchuk K, Szczepański P, Shrotre A, Haddad M, Chagnes A (2017) Effects of structural changes of new organophosphorus cationic exchangers on solvent extraction of cobalt, nickel and manganese from acidic chloride media. RSC Advances 7: 5660-5668.

7. Omelchuk K, Stambouli M, Chagnes A (2018) Investigation of aggregation and acid dissociation of new cationic exchangers for liquid-liquid extraction. Journal of Molecular Liquids 262: 111-118.

8. Omelchuk K, Chagnes A (2018) New cationic exchangers for the recovery of cobalt(II), nickel(II) and manganese(II) from acidic chloride solutions: modelling of extraction curves. Hydrometallurgy 180: 96-103.

9. Chagnes A (2020) Simulation of solvent extraction flowsheets by a global model combining physicochemical and engineering approaches -Application to cobalt(II) extraction by D2EHPA. Solvent Extraction and Ion Exchange 38(1): 3-13. 